\title{
Diversity and Distribution of Archaea in the Mangrove Sediment of Sundarbans
}

\author{
Anish Bhattacharyya, ${ }^{1}$ Niladri Shekhar Majumder, ${ }^{2}$ Pijush Basak, \\ Shayantan Mukherji, ${ }^{3}$ Debojyoti Roy, ${ }^{1}$ Sudip Nag, ${ }^{1}$ \\ Anwesha Haldar, ${ }^{4}$ Dhrubajyoti Chattopadhyay, ${ }^{1}$ Suparna Mitra, ${ }^{5}$ \\ Maitree Bhattacharyya, ${ }^{1}$ and Abhrajyoti Ghosh ${ }^{3}$ \\ ${ }^{1}$ Department of Biochemistry, University of Calcutta, 35 Ballygunge Circular Road, Kolkata, West Bengal 700019, India \\ ${ }^{2}$ Roche Diagnostics India Pvt. Ltd., Block 4C, Akash Tower, Near Ruby Hospital, 781 Anandapur, Kolkata 700107, India \\ ${ }^{3}$ Department of Biochemistry, Bose Institute, P1/12, C. I. T. Road, Scheme VIIM, Kolkata, West Bengal 700054, India \\ ${ }^{4}$ Department of Geography, University of Calcutta, 35 Ballygunge Circular Road, Kolkata, West Bengal 700019, India \\ ${ }^{5}$ Norwich Medical School, University of East Anglia and Institute of Food Research, Norwich Research Park, Norwich, \\ Norfolk NR4 7UA, UK
}

Correspondence should be addressed to Dhrubajyoti Chattopadhyay; dhrubajyotic@gmail.com, Suparna Mitra; suparna.mitra.sm@gmail.com, Maitree Bhattacharyya; bmaitree@gmail.com, and Abhrajyoti Ghosh; aghosh78@gmail.com

Received 30 March 2015; Revised 25 June 2015; Accepted 14 July 2015

Academic Editor: William B. Whitman

Copyright (C) 2015 Anish Bhattacharyya et al. This is an open access article distributed under the Creative Commons Attribution License, which permits unrestricted use, distribution, and reproduction in any medium, provided the original work is properly cited.

\begin{abstract}
Mangroves are among the most diverse and productive coastal ecosystems in the tropical and subtropical regions. Environmental conditions particular to this biome make mangroves hotspots for microbial diversity, and the resident microbial communities play essential roles in maintenance of the ecosystem. Recently, there has been increasing interest to understand the composition and contribution of microorganisms in mangroves. In the present study, we have analyzed the diversity and distribution of archaea in the tropical mangrove sediments of Sundarbans using $16 \mathrm{~S}$ rRNA gene amplicon sequencing. The extraction of DNA from sediment samples and the direct application of $16 \mathrm{~S}$ rRNA gene amplicon sequencing resulted in approximately $142 \mathrm{Mb}$ of data from three distinct mangrove areas (Godkhali, Bonnie camp, and Dhulibhashani). The taxonomic analysis revealed the dominance of phyla Euryarchaeota and Thaumarchaeota (Marine Group I) within our dataset. The distribution of different archaeal taxa and respective statistical analysis (SIMPER, NMDS) revealed a clear community shift along the sampling stations. The sampling stations (Godkhali and Bonnie camp) with history of higher hydrocarbon/oil pollution showed different archaeal community pattern (dominated by haloarchaea) compared to station (Dhulibhashani) with nearly pristine environment (dominated by methanogens). It is indicated that sediment archaeal community patterns were influenced by environmental conditions.
\end{abstract}

\section{Introduction}

Archaea, representing the third domain of life, were originally anticipated to thrive under extreme environments, such as hydrothermal vents, hot water springs, salt brines, and extremely acidic and anoxic environments, where they contribute significantly towards the maintenance of the biogeochemical cycles [1-7]. However, with the advent of molecular techniques, it has become increasingly evident that archaea are much more widespread and metabolically diverse than originally postulated. A considerable portion of the microbial communities in a wide variety of "nonextreme" environments, for example, soil, ocean, and lakes, is constituted by archaea [8-13]. Despite the increasing interest to understand the ecophysiology of archaea, the lack of knowledge with respect to mesophilic and cold-adopted archaea is still enormous $[9,14,15]$. 
Mangrove wetlands are typical example of mesophilic and moderately halophilic environmental niches. They are commonly situated at the intertidal zones along the tropical and subtropical coasts and play a very important role in shaping the coastal ecology [16]. Mangrove forests are considered to be highly productive niche that support detritus-based food web [16, 17]. Particularly, in tropical mangroves, the high turnover rates for organic matters and nutrient cycling between the ocean and terrestrial habitats makes it the most productive ecosystem in the world [17]. The high primary productivity of mangroves implies a high demand for nutrients essential for plant growth and this appears to be achieved by a highly efficient system of nutrient trapping, uptake, and recycling in mangrove ecosystem [18]. The diverse microbial communities residing in the mangroves play important role in transformation of nutrients in the environment. While the importance of bacteria and fungi in mangrove biogeochemical cycles is well established, our knowledge of archaea in mangrove habitats remains extremely limited [16].

Sundarbans is the world's largest tidal halophytic mangrove ecosystem covering 20,400 square kilometers (7,900 sq mi) of area and has been recognized as a UNESCO World Heritage site. Situated in the delta of Ganges, Meghna, and Brahmaputra rivers on the Bay of Bengal, Sundarbans is shared between India and Bangladesh. This mangrove ecosystem is the home for diverse flora and fauna, including mangrove plant species like sundari (Heritiera fomes), goran (Ceriops decandra), geoa (Excoecaria agallocha), keora (Sonneratia apetala), and so forth, and the world's famous endangered royal Bengal tiger (Panthera tigris tigris). Microbial communities play an important role in generation of detritus in mangrove areas and Sundarbans is one such ecotype where microbes have been shown to be involved in biogeochemical cycling of the nutrients [18-20]. Despite global advancement in understanding the microbial diversity and role of microbes in different mangrove environments, little has been performed in Sundarbans [21, 22]. In a very recent study, a detailed description of the bacterial diversity has been presented in the backdrop of seasonal changes [23]. However, no data are yet available regarding the abundance and diversity of archaea in Sundarbans.

Hitherto, most of the research on mangrove environments has focused on understanding the diversity and functions of bacteria and fungi [23-26], and very little is known about archaeal assemblages in mangrove $[16,27,28]$. In order to gain new insight into the archaeal community patterns and the influence of environmental conditions in the mangrove sediments and to build foundational information for future research, we have investigated the archaeal diversity in the sediments of Indian Sundarbans employing 454pyrosequencing.

\section{Materials and Methods}

2.1. Ethics Statement. No specific permits were required for the described field studies, which complied with all relevant regulation. The studied locations are not privately owned. Moreover, the study did not involve endangered or protected species. Indeed, the Indian Coastal Zone Management (ICZM) authority of the state of West Bengal, India, has approved this experimental exercise.

2.2. Study Area and Sediment Sampling. Samples were collected in triplicate from surface $(2 \mathrm{~cm})$ and subsurface $(32 \mathrm{~cm})$ sediments of the Sundarbans mangrove wetland, which is located on the northeastern coast of India (Figure 1). The samples were collected from three different stations; for example, Godkhali (station A; $22^{\circ} 06^{\prime} 32.570^{\prime \prime} \mathrm{N} 88^{\circ} 46^{\prime} 22.220^{\prime \prime} \mathrm{E}$ ), Bonnie camp (station B; $21^{\circ} 49^{\prime} 53.581^{\prime \prime} \mathrm{N} 88^{\circ} 36^{\prime} 44.860^{\prime \prime} \mathrm{E}$ ), and Dhulibhashani (station $\mathrm{C} ; 21^{\circ} 37^{\prime} 40.837^{\prime \prime} \mathrm{N} 88^{\circ} 33^{\prime} 47.762^{\prime \prime} \mathrm{E}$ ) spanning $90 \mathrm{~km}$ along the tidal gradient from the shoreline (Figure 1). In June 2013, the sediment samples were collected in triplicate from each station. A sediment corer $(50 \mathrm{~cm}$ depth, $6 \mathrm{~cm}$ diameter) was used to collect the top $32 \mathrm{~cm}$ of sediments. The uppermost surface layer $(0-2 \mathrm{~cm})$ and deeper subsurface layer (30$32 \mathrm{~cm}$ ) were sampled and immediately sieved by a $2 \mathrm{~mm}$ mesh in the field. The sieved fractions were stored in sealed sterile polypropylene containers and brought to the laboratory. Upon arrival, a portion of each sediment sample was flash-frozen at $-80^{\circ} \mathrm{C}$ for polyaromatic hydrocarbon (PAH) analysis and DNA extraction. The remaining sediments were stored at $4^{\circ} \mathrm{C}$ for other analytical procedures such as nutrients and heavy metals estimation. The individual collection from each sampling station was used for physicochemical analysis and in case of DNA extraction for sequencing analysis; three individual collections were mixed to homogeneity to generate a representative composite sample.

2.3. Sediment Analyses and Site Climate. Microbiological and biochemical analyses were performed with the field moist sediments. Physical and chemical analyses were carried out with air-dried sediment samples. The sediment $\mathrm{pH}$ was measured in $1: 2.5$ sediment-water suspensions and found to be alkaline. The total organic carbon (TOC) was measured by the methods described previously $[29,30]$. Briefly, TOC in a sample was determined by combusting the air-dried sediment sample catalytically in oxygen atmosphere into instrument chamber at $500^{\circ}-900^{\circ} \mathrm{C}$ and the resulting carbon dioxide gas was detected by a nondispersive infrared (NDIR) detector in an Aurora TOC Analyzer that was calibrated to directly display the detected carbon dioxide mass. This mass was proportional to the TOC mass in the sediment sample and calculated as total mass of carbon per unit of sediment sample.

Conductivity and salinity were measured in situ with Hach Portable Meters (HQ40d). Measured salinity was expressed in parts per thousand (ppt) or $\mathrm{gm} \mathrm{Kg}^{-1}$ as described previously [31]. Nutrients like inorganic nitrogen (ammonia, nitrite, and nitrate), soluble phosphate, and reactive silicate were measured after quantitative extraction in respective buffering conditions following standard methodologies [32]. Briefly, nitrite was measured after complexing with sulphanilamide followed by a coupling reaction with $\mathrm{n}(1-$ napthyl)-ethylenediamene dihydrochloride, which forms an azo dye upon coupling. The resulting azo dye was measured 


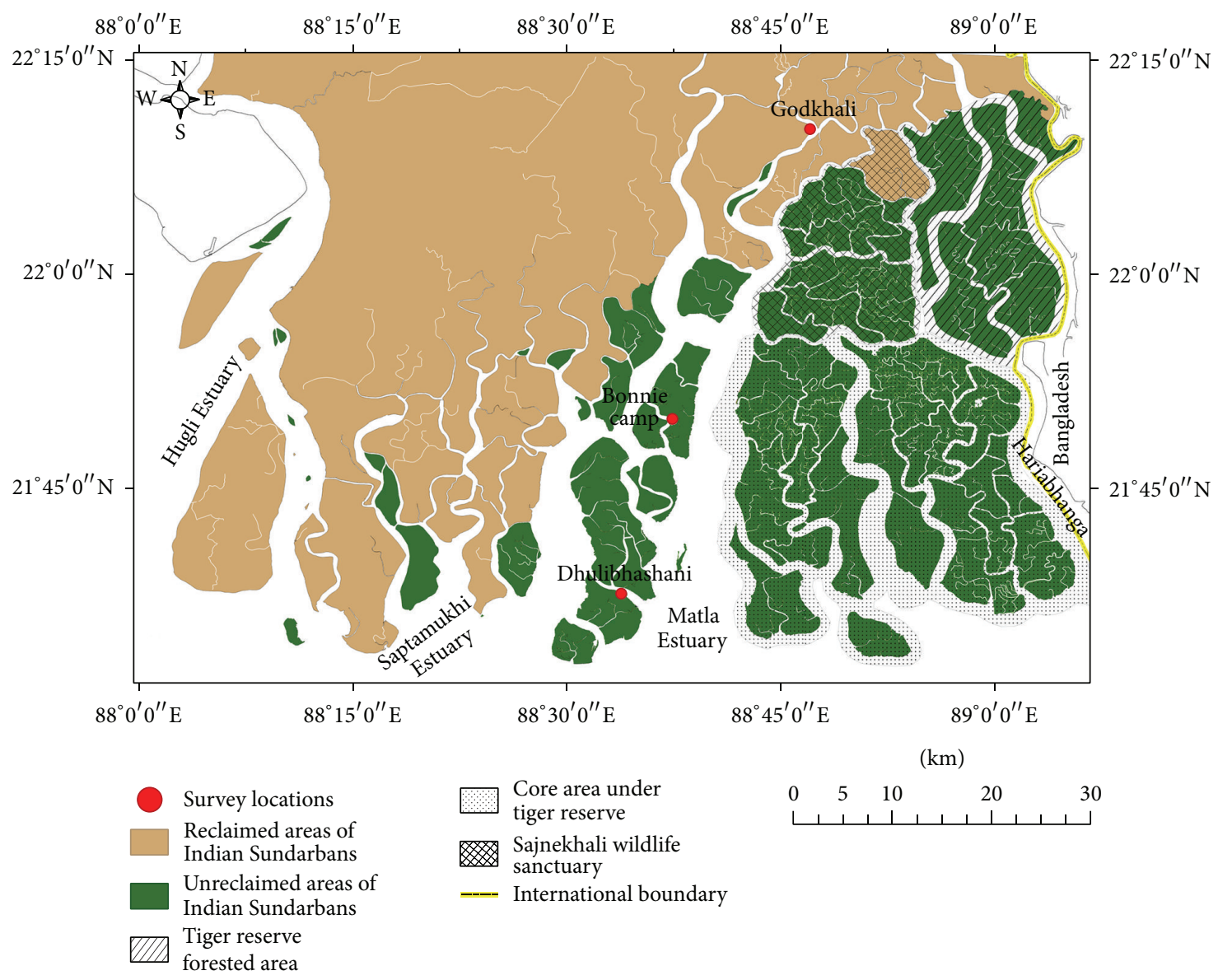

Figure 1: Geographical location of the sampling stations (Jharkhali-A, Sahidnagar-B, and Godkhali-C) in Indian Sundarbans. Coordinates of the sampling points and description of the stations are presented in Section 2.

spectrophotometrically at $543 \mathrm{~nm}$. The nitrate, in contrary, was quantitatively reduced to nitrite using cadmium (Cd) granules prior to measurement. The total nitrite was then measured spectrophotometrically as described earlier and further subtraction of the measured value of free nitrite in the sediment resulted in determination of nitrate in the sample. Ammonia was measured in a reaction with hypochlorite under alkaline condition, which results in formation of monochloramine. In a successive reaction with phenol and nitroprusside, monochloramine was converted into indophenol blue, which was measured spectrophotometrically at $630 \mathrm{~nm}$. The soluble phosphate was measured using acidified molybdate reagent, which yields phosphomolybdate complex upon reaction with soluble phosphate. This complex was further reduced into molybdenum blue and measured spectrophotometrically at $880 \mathrm{~nm}$. The reactive silicate was measured using the formation of yellow silicomolybdic acid in presence of molybdate under acidic condition.

Organic pollutants (polyaromatic hydrocarbons, $\mathrm{PAH}$ ) were measured using a combined gas chromatography and mass spectrometry (GC/MS) method described previously $[33,34]$. Heavy metals in the sediment samples were assessed using atomic absorption spectrophotometric technique (Agilent Technologies, CA, USA).
2.4. Sediment DNA Isolation. For 454-pyrosequencing, each of the sediment samples from a station (total $n=3$ ) and aliquots of homogenized sediment of $0.5 \mathrm{~g}$ were subjected to DNA extraction using the MoBio PowerSoil DNA Isolation Kit (MoBio Laboratories, Carlsbad, CA). After the extraction, DNA from all three samples from each sampling station was pooled together (approximately $200 \mathrm{ng}$ of DNA from each extraction), and the pooled DNA was concentrated in a speed vacuum centrifuge $(2,500 \mathrm{rpm}, 30 \mathrm{~min})$ to a final volume of $25 \mu \mathrm{L}$ (approximately $24 \mathrm{ng} \mu \mathrm{L}^{-1}$ ). A NanoDrop (Thermo Scientific, Wilmington, DE, USA) spectrophotometer was used to quantify the extracted pooled DNA and to measure other important parameters for DNA quality, such as the ratio of absorbance at 260/280 $\mathrm{nm}$ and 260/230 $\mathrm{nm}$.

2.5. PCR Amplification of Archaeal 16S rRNA Gene. To analyze archaeal diversity, the V3-V5 region of archaeal $16 \mathrm{~S}$ rRNA gene was amplified by PCR. The PCR reaction $(25 \mu \mathrm{L})$ contained $5 \mu \mathrm{L}$ of 5 -fold Phusion GC buffer (Finnzymes, Vantaa, Finland), $200 \mu \mathrm{M}$ of each of the four deoxynucleoside triphosphates, $1.5 \mathrm{mM} \mathrm{MgCl}_{2}, 4 \mu \mathrm{M}$ of each primer (see Table S1 of the Supplementary Material available online at http://dx.doi.org/10.1155/2015/968582), 2.5\% 
DMSO, $1 \mathrm{U}$ of Phusion High Fidelity Hot Start DNA polymerase (Finnzymes), and $25 \mathrm{ng}$ of pooled sediment DNA. The following thermal cycling scheme was used on a Veriti Thermal Cycler (Applied Biosystems, USA): initial denaturation at $98^{\circ} \mathrm{C}$ for $5 \mathrm{~min}, 25$ cycles of denaturation at $98^{\circ} \mathrm{C}$ for $45 \mathrm{~s}$, and annealing at $68^{\circ} \mathrm{C}$ for $45 \mathrm{~s}$, followed by extension at $72^{\circ} \mathrm{C}$ for $30 \mathrm{~s}$. The final extension was carried out at $72^{\circ} \mathrm{C}$ for $5 \mathrm{~min}$. Negative controls were performed by using the reaction mixture without template. Primer sequences for amplification of the V3-V5 region [35] as well as 454 adaptors with the unique MIDs for each sample are listed in Table S1.

2.6. Library Preparation. PCR amplicons were evaluated by electrophoresis on a 1.5\% agarose gel. The amplicon library was purified with Agencourt AMPure XP beads (Beckman Coulter Inc., Canada) and quantified by fluorometry using the Quant-iT PicoGreen dsDNA Assay Kit (Invitrogen, Burlington, ON) according to the Roche 454 "Amplicon Library Preparation Method Manual" of the GS Junior Titanium Series (454 Life Sciences, USA). Pooled amplicons were diluted as recommended and amplified by emulsion PCR on a Thermal Cycler 9700 (Applied Biosystem) according to the Roche 454 "emPCR Amplification Method Manual Lib-L" (454 Life Sciences, USA).

2.7. Sequencing and Data Processing. Pyrosequencing was performed for 200 cycles on a Roche 454 GS Junior sequencing instrument according to the manufacturer's protocol (454 Life Sciences, USA). All reads were filtered using the standard read rejecting filters of the GS Junior sequencer, namely, key pass filters, dot and mixed filters, signal intensity filters, and primer filters (454 Sequencing System Software Manual, V 2.5.3, 454 Life Sciences, USA). Raw sequencing and processing data was carried out using a combination of mothur (software version 1.28.0) and Ribosomal Database Project (RDP-II). The raw data were subjected to initial quality trimming using the mothur software and all reads having an average quality value of $<20$ were discarded. Then we removed the number of chimeric sequences by using UCHIME algorithm. Then the chimeric free reads were further screened for the presence of ambiguous bases and any reads which have a length $<200$ were discarded and forward primer sequence was removed from the final dataset. The obtained processed reads were then demultiplexed to separate sample based on the $10 \mathrm{bp}$ MID sequence and any reads which do not match the MID were discarded. The high quality reads were then aligned to archaeal $16 \mathrm{~S}$ rRNA sequences and clustering was performed at 97\% similarity; using the RDP pipeline, a representative sequence from each cluster was selected based on abundance using the sequence selection tool. The representative sequences obtained from each cluster were then classified using the naïve Bayesian Classifier (Ribosomal Data Project, release 10) at a bootstrap confidence of 80 .

2.8. Taxonomic Annotation. After quality trimming all the sequence reads were aligned against the SILVA, which is a curated ribosomal RNA sequence database using BLASTN
$[36,37]$. The resulting output files of read sequences were imported and analyzed using the paired-end protocol of MEGAN [38] to obtain taxonomic profiles as described earlier [39]. When processing the BLAST output files by MEGAN we used parameter settings of "Min Score $=35$," "Top Percent $=100$," "Min Support $=5$," and "Minimum Sequence Complexity Threshold $=0.44$." Reads which did not have any match to the respective database were placed under "No hit" node. Any reads that were originally assigned to a taxon that did not meet our selected threshold criterion were pushed back using the lowest common ancestor (LCA) algorithm to higher nodes where the threshold was met. After importing the datasets in MEGAN we obtained a set of MEGAN-proprietary "rma files" for each data mapped onto the NCBI taxonomy based on our selected threshold for tree visualization purpose.

All six RMA files were normalized to the smallest data set size (without including reads classified as not having a taxonomic assignment) to allow intersample comparison of taxonomic abundances and to obtain comparative tree view for all samples. Comparative abundance of read counts at different levels of NCBI taxonomy (class, order, family, genus, and species) was exported from all sample comparison-file for later statistical analyses.

2.9. Statistical Analyses. Hierarchical cluster analyses have been performed using R 3.0.2 [40], with species abundance data where Pearson's correlation is used for clustering the probes/genes (rows) and Spearman rank correlation is used for clustering the sample datasets (cols), with complete linkage.

Composition (presence/absence) data were also analyzed to compare the community structure. SIMPER analyses were used to determine which taxa/function contributed most to the observed differences. Further data were analyzed using common multivariate ordination techniques: Nonmetric Multidimensional Scaling (NMDS) using Bray Curtis distance. To understand the influence of physicochemical parameters in different sampling stations, Principal Component Analysis (PCA) was performed. Additionally, we have performed correspondence analyses on genomic data as well as on $\mathrm{PAH}$ (polyaromatic hydrocarbons) data.

We have also plotted the genomic data using Voronoi diagram, which is a partitioning of a plane into regions based on distance to points in a specific subset of the plane. In this plot we have highlighted 6 major phyla.

2.10. Nucleotide Sequence Accession Numbers. All 454-GS Junior sequence data from this study were submitted to the NCBI Sequence Read Archive (SRA) under accession numbers SRR1632262 (Godkhali_surface), SRR1632263 (Godkhali_subsurface), SRR1632258 (Bonnie camp_surface), SRR1632259 (Bonnie camp_subsurface), SRR1632260 (Dhulibhashani_surface), and SRR1632261 (Dhulibhashani_subsurface).

\section{Results}

3.1. Environmental Parameters. Physicochemical characteristics such as $\mathrm{pH}$, dissolved oxygen, saturation, total carbon, 
TABLE 1: Environmental parameters of sampling sites analyzed in this study.

\begin{tabular}{lcccccccc}
\hline Sample & Site & Latitude $^{\circ} \mathrm{N}$ & Longitude $^{\circ} \mathrm{E}$ & Depth $(\mathrm{cm})$ & $T\left({ }^{\circ} \mathrm{C}\right)^{*}$ & Salinity $(\mathrm{psu})^{*}$ & $\mathrm{pH}^{*}$ & $\mathrm{DO}^{\prime}(\mathrm{mg} / \mathrm{L})^{*}$ \\
\hline Surface & Godkhali & $22^{\circ} 06^{\prime} 32.570^{\prime \prime}$ & $88^{\circ} 46^{\prime} 22.220^{\prime \prime}$ & 2 & 31.30 & 21.00 & 7.88 & 7.32 \\
Subsurface & Godkhali & $22^{\circ} 06^{\prime} 32.570^{\prime \prime}$ & $88^{\circ} 46^{\prime} 22.220^{\prime \prime}$ & 32 & 31.80 & 20.80 & 7.85 & 7.24 \\
Surface & Bonnie camp & $21^{\circ} 49^{\prime} 53.581^{\prime \prime}$ & $88^{\circ} 36^{\prime} 44.860^{\prime \prime}$ & 2 & 32.10 & 21.60 & 7.98 & 7.15 \\
Subsurface & Bonnie camp & $21^{\circ} 49^{\prime} 53.581^{\prime \prime}$ & $88^{\circ} 36^{\prime} 44.860^{\prime \prime}$ & 32 & 32.50 & 21.40 & 7.97 & 7.05 \\
Surface & Dhulibhashani & $21^{\circ} 37^{\prime} 40.837^{\prime \prime}$ & $88^{\circ} 33^{\prime} 47.762^{\prime \prime}$ & 2 & 29.70 & 22.80 & 7.96 & 7.15 \\
Subsurface & Dhulibhashani & $21^{\circ} 37^{\prime} 40.837^{\prime \prime}$ & $88^{\circ} 33^{\prime} 47.762^{\prime \prime}$ & 32 & 30.10 & 22.10 & 7.95 & 7.02 \\
\hline
\end{tabular}

* Average of three independent measurements, $n=3$.

total nitrogen, and salinity were estimated for surface and subsurface samples from all the three stations in the present study (Table 1 and Table S2). The environmental parameters, for example, salinity, temperature, dissolved oxygen, $\mathrm{pH}$, and saturation were measured in situ (Table 1). Temperature and salinity ranged from 29.7 to $32.8^{\circ} \mathrm{C}$ and from 21 to $22.8 \mathrm{psu}$, respectively. The lowest temperature and highest salinity were recorded in Dhulibhashani.

Measurement of $\mathrm{NO}_{2}{ }^{-}, \mathrm{NO}_{3}{ }^{-}$, and $\mathrm{NH}_{4}{ }^{+}$in the surface and subsurface samples from all the three sampling stations revealed a differential pattern for these nitrogen species (Table S2). Ammonia was found maximum in the sediment samples of Godkhali, while it was minimum in the sediment of Dhulibhashani $(P<0.05)$. Nitrite was found negligible in all the stations confirming very high rate of nitrification, resulting in nitrate formation, which was evenly detected in all three sampling stations (Table S1). Other parameters such as phosphate, sulphate, and silicate were found evenly distributed in all the sampling stations possibly due to regular inundation.

Heavy metals have been shown to play a pivotal anthropogenic role in the marine environment. Previously, it has been shown that heavy metals like Fe, $\mathrm{Zn}, \mathrm{Cu}, \mathrm{Mn}, \mathrm{Hg}, \mathrm{Pb}, \mathrm{Ni}$, $\mathrm{Cr}$, and $\mathrm{Cd}$ are present in the Sundarbans estuaries [41-44]. To ascertain the global ecological impact of different heavy metals in the present study, concentrations of heavy metals like $\mathrm{Fe}, \mathrm{Cd}, \mathrm{Zn}, \mathrm{Cu}, \mathrm{Ni}$, and $\mathrm{Pd}$ were measured in surface and subsurface samples collected from all the three stations (Table S2). Heavy metal estimates for the Sundarbans sediment found in our study were fairly consistent with previously found results [45].

3.2. Archaeal Community Structure Revealed by $16 S$ rRNA Gene Based Analysis. We analyzed archaeal 16S rRNA gene (SSU) amplicons prepared from six sediment samples originated from three sampling stations at two different depths. After quality filtering, denoising, and removal of potential chimeric sequences of pyrosequencing dataset, this resulted in recovery of $1,41,816$ sequences with an average length ranges between 500 and 510 bases (506 bp average) (Table 2). Within our sequence dataset, we were able to assign 1,39,953 sequences to the domain archaea and to classify all of these sequences below domain level using BLASTN 2.2.25+ in SILVA database and MEGAN (Table 2). The classified sequences were affiliated to two archaeal phyla and five archaeal classes or similar phylogenetic group (Figure 2 and
TABLE 2: Sample statistics.

\begin{tabular}{lcc}
\hline Samples & $\begin{array}{c}\text { Total number } \\
\text { of reads } \\
\text { sequenced }\end{array}$ & $\begin{array}{c}\text { Assigned against } \\
\text { SILVA using } \\
\text { BLASTN 2.2.25+ } \\
\text { and MEGAN }\end{array}$ \\
\hline Godkhali_surface & 15,939 & 15,647 \\
Godkhali_subsurface & 23,437 & 23,091 \\
Bonnie camp_surface & 15,371 & 15,120 \\
Bonnie camp_subsurface & 15,788 & 15,654 \\
Dhulibhashani_surface & 33,771 & 33,395 \\
Dhulibhashani_subsurface & 37,510 & 37,046 \\
\hline
\end{tabular}

Figure S1). Euryarchaeota often was the most abundant phylum (36-60\%) and Thermoplasmata was the predominant class across all samples (39-62\%) (Figure S1). Besides Euryarchaeota, Thaumarchaeota (Marine group I) was found to be highly abundant in all the samples (Table S3). Within euryarchaeal sequences, a number of members of the class Halobacteria, for example, Halosarcina, Halorientalis, Halolamina, Halorhabdus, Halogranum, Haloferax, Halomarina, Halorussus, Haloplanus, and Halarchaeum, and of the class Methanomicrobia, for example, Methanosarcina, Methermicoccus, Methanocella, Methanococcoides, Methanosalsum, Methanolobus, and Methanogenium were detected (Figure 2). Besides, few sequences were also affiliated to classes Thermoplasmata and Methanobacteria. Unfortunately, within our datasets, we could not detect any representative of the archaeal phyla Crenarchaeota, Korarchaeota, Nanoarchaeota, and Nanohaloarchaeota due to lower coverage of the degenerate primers used in this study.

3.3. Diversity and Species Richness of Archaeal Communities. A diversity index is a mathematical measure of species diversity in a community. Diversity indices provide important information about community composition rather than only species richness (i.e., the number of species present); and simultaneously they also take the relative abundances of different species into account. We evaluated the archaeal diversity and evenness using the normalized dataset. Considering all the sampling sites, the Shannon-Weaver $\left(H^{\prime}\right)$ index varied from 0.67 to 1.08 and the Simpson diversity $\left(1-\lambda^{\prime}\right)$ index varied from 0.29 to 0.52 (Table 3 ). Such variations of diversity indicated that the archaeal diversity is higher at the surface samples both in Bonnie camp and Godkhali. 


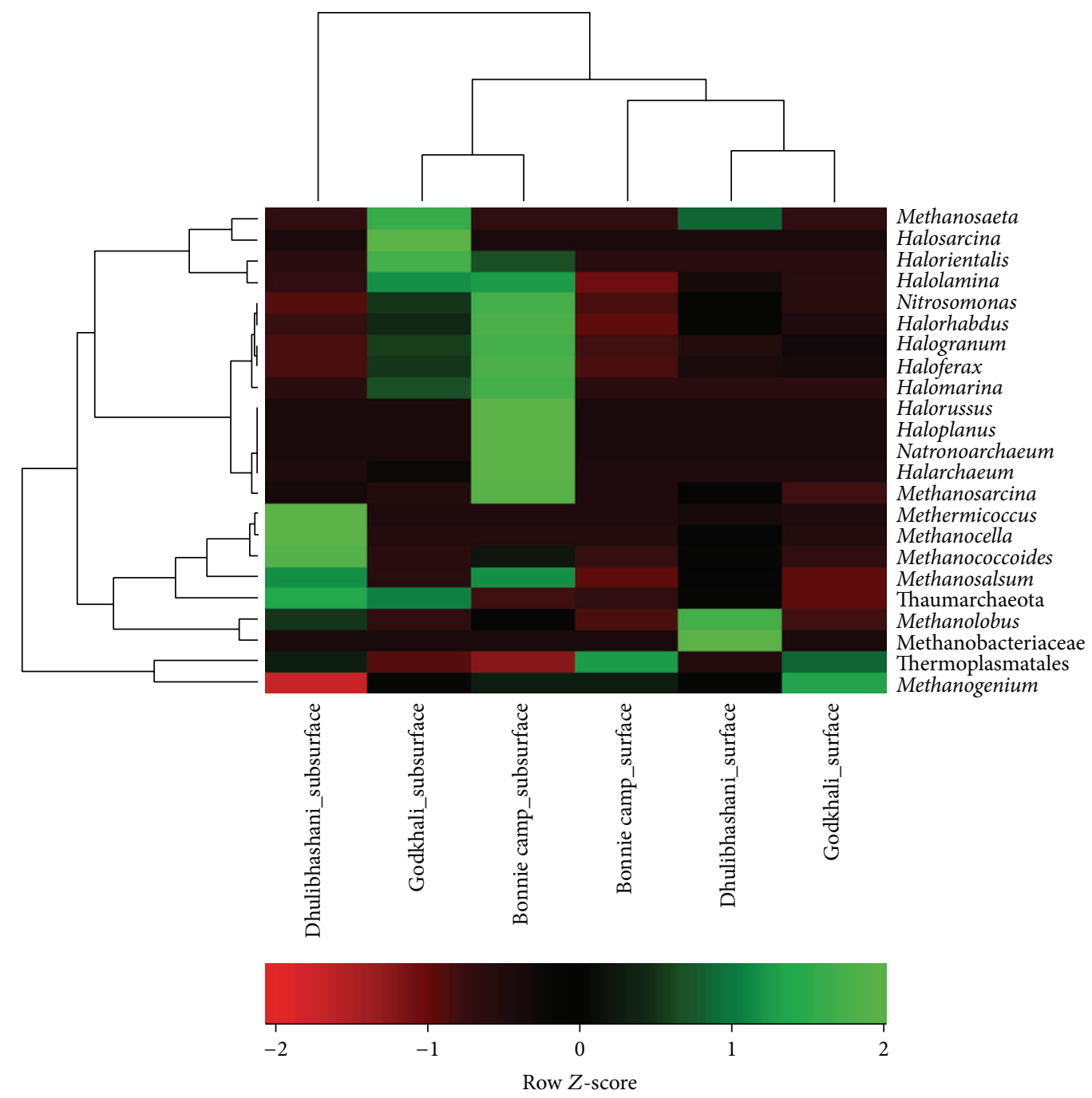

FIGURE 2: Hierarchical clustering (complete-linkage) heat map generated from taxonomic abundance profile (using Spearman's rank correlation) reflecting spatial distribution of archaeal class in the sediment of Sundarbans (using Pearson's correlation).

However, in Dhulibhashani, archaeal diversity was found to be almost similar both at the surface and at subsurface level with a marginally higher diversity in subsurface sample. The Pielou index $\left(J^{\prime}\right)$ was between 0.23 and 0.37 and the Margalef $(d)$ index was between 1.52 and 3.69 (Table 3). Diversity and evenness are more informative for describing community composition than simple phylotype richness levels. Community diversity, as reflected by the Shannon index, was highest in Bonnie camp_subsurface and lowest in Godkhali_subsurface and is by definition generally correlated positively with the number of unique phylotypes and/or with greater community evenness.

3.4. Taxonomic Assignments and Statistics. In addition to surveying archaeal diversity at the surface and subsurface sediments of three sites in Sundarbans, pyrosequencing also allowed assessment of the relative abundance of the taxonomic levels of archaea detected. A total of 23 genera (genus/order/family) were commonly shared between six samples (Figure 2 and Figure S1). Interestingly, the dominant class/phylum showed some geographical characteristics. For example, Halobacteria were highly abundant in the subsurface layers of the representative samples from Godkhali and Bonnie camp. In contrary, Methanomicrobia were only dominant in the subsurface sediment of Dhulibhashani.

Cluster analysis showed that the archaeal community detected in the subsurface sediment of Dhulibhashani was the most dissimilar of all the sediment samples tested (Figure 2). Additionally, among the subsurface sediments, the most diverse archaeal community was detected in this sediment. Among others, there is a clear separation of two types of samples, surface and subsurface. The surface sediments have shown an overall similarity among Godkhali and Bonnie camp while Dhulibhashani surface showed a different community profile.

Further we have performed Nonmetric Multidimensional Scaling (NMDS) to compare the community composition using presence/absence data. NMDS employs an iterative 


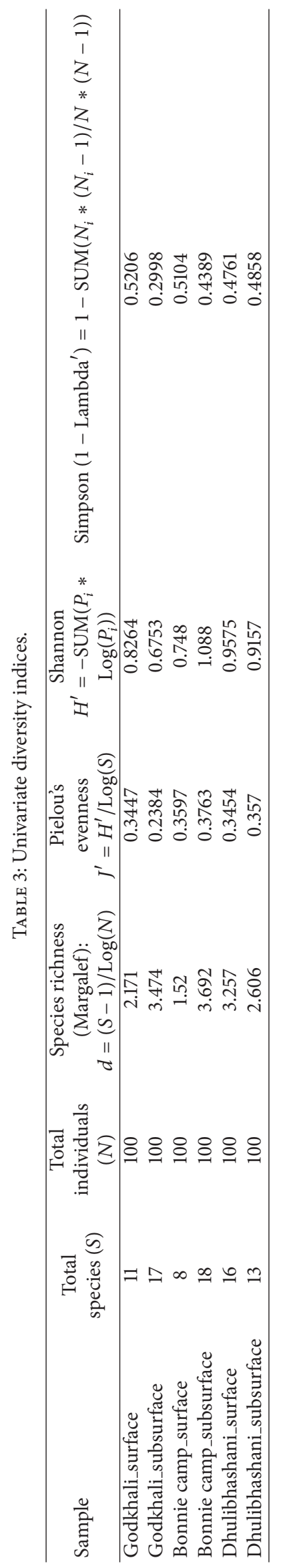




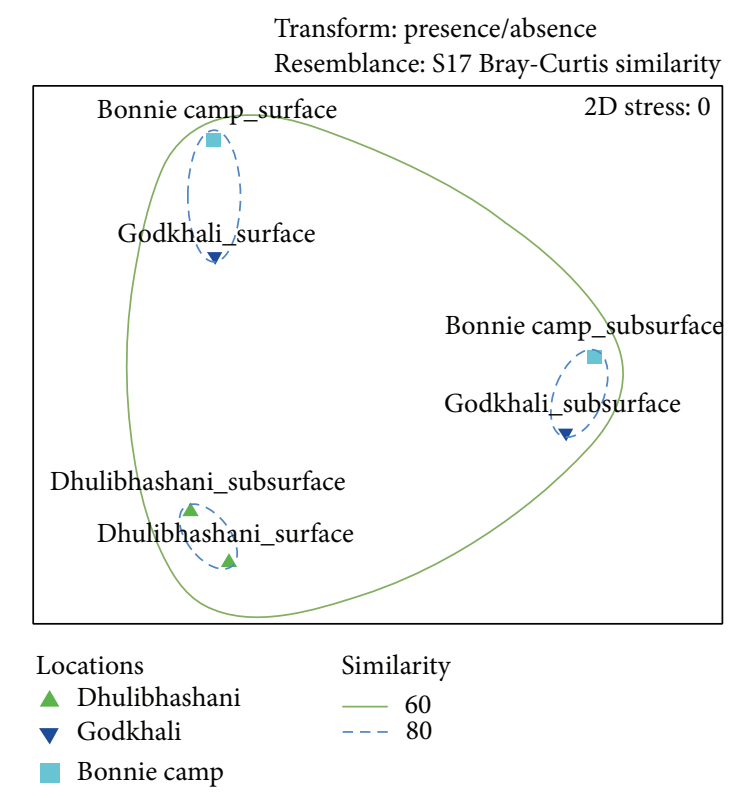

FIGURE 3: Archaeal community compositional structure in the sediments of Sundarbans indicated by Nonmetric Multidimensional Scaling (NMDS) using Bray-Curtis distance. Gene abundance data was transformed based on presence/absence before creating BrayCurtis resemblance matrix for NMDS analysis (showing similarity based on community composition only).

algorithm that optimizes the position of samples into a lowdimensional space minimizing the difference between rankorder of multivariate ecological dissimilarity and distances in NMDS space (Figure 3). From the figure it is easily observed that despite the presence of very few abundant taxa in more than one sample, surface and subsurface communities from different sampling stations or locations (Godkhali and Bonnie camp) were more closely related to each other than to samples from the same location. Samples from Dhulibhashani show similar results to cluster analyses, showing much different community structure than the other locations for both surface and subsurface samples. To this end we believe that the presence or absence of certain taxonomic groups in the sediment of Dhulibhashani is probably due its proximity to the open ocean (Bay of Bengal) and the nutritional status of the sediment.

Furthermore, our PCA analysis revealed that the physicochemical parameters influence sampling stations differentially. The first PCA axis showed high positive correlations with heavy metals $\mathrm{Zn}, \mathrm{Pb}$, and $\mathrm{Cu}$ (Figure 4(a)). Samples from Bonnie camp showed high positive correlations with all of these heavy metals. In contrary, samples from Godkhali showed positive correlations with heavy metals $\mathrm{Cd}$ and $\mathrm{Fe}$ (Figure 4(a)). To this end, PCA analysis revealed that both of these sampling stations at Godkhali and Bonnie camp were at an elevated risk compared to Dhulibhashani, regarding heavy metal pollution. Notably, these two sampling stations also showed positive correlations with $\mathrm{pH}, \mathrm{DO}$, silicate, nitrite, ammonia, saturation, and total nitrogen (Figure 4(a)).
Dhulibhashani, on the other hand, showed positive correlations with TOC, nitrate, sulphate, and salinity (Figure 4(a)).

Further, we have performed correspondence analysis (CA) to compare the influence of abundant taxonomic groups and polyaromatic hydrocarbons (PAH) in these sampling sediments (Figures 4(b) and 4(c)). The correspondence analysis comparing abundant taxonomic groups in the sampling stations clearly indicated that the subsurface sediments from Godkhali and Bonnie camp were heavily dominated by Halobacteriaceae (Figure 4(b)), whereas surface archaeal communities in these sampling stations were dominated by Methanomicrobiaceae, Methermicoccaceae, and Methanocellaceae (Figure 4(b)). Both the surface and subsurface archaeal communities in Dhulibhashani were heavily dominated by Methanosarcinaceae and Methanobacteriaceae (Figure 4(b)). To summarize, methanogens were commonly encountered in the surface sediments of all three stations. However, while Halobacteriaceae dominated the subsurface archaeal population in Godkhali and Bonnie camp, methanogenic Methanosarcinaceae and Methanobacteriaceae dominated the subsurface sediment of Dhulibhashani.

Correspondence analysis, performed to understand the influence of PAHs in the sediments of the sampling stations, revealed that both the surface and subsurface sediments of Godkhali and Bonnie camp correlated with the detected PAH congeners (Figure 4(c)). In contrary, surface and subsurface sediments of Dhulibhashani showed little correlation to any of the identified PAHs. To this end, we believe that the pattern of correlation of PAHs in the sediments of Godkhali and Bonnie camp is in agreement with the detection of Halobacteriaceae, the most active hydrocarbon degrading archaeal representative, in the subsurface sediments of these stations. In general, hydrocarbons, by virtue of being hydrophobic in nature, are scarcely soluble in water and tend to adsorb readily onto organic matter, particularly sediments. In an environment like Sundarbans, surface sediments are in general more dynamic due to regular inundation. The hydrocarbons, therefore, remained mostly absorbed in the sediments and our data clearly shows that subsurface sediments contain more PAHs compared to surface sediments.

Finally, we have generated Voronoi plot (Figure 5), which describes the proportionate taxonomic composition pattern for each sample as a partition of a plane.

\subsection{Multivariate SIMPER (Similarity Percentage) Analysis.}

To reveal differences between three sampling stations, Godkhali, Bonnie camp, and Dhulibhashani, and to identify major taxonomic groups that contributed to the similarities or dissimilarities, SIMPER (Similarity Percentage) analysis was performed (Tables 4(a), 4(b), and 4(c)). At the regional scale, there were differences observed at order/family/genus level between three sampling stations. Overall, distribution of taxa was found similar in Godkhali and Bonnie camp with Thermoplasmatales being the major contributor towards the similarity (23.3\%), and with only exception of Methanosarcina, the relative abundance of which was higher in Bonnie camp. In general, SIMPER analysis targeting relative abundance of taxa in different stations revealed higher relative abundance of class Halobacteria in Godkhali 


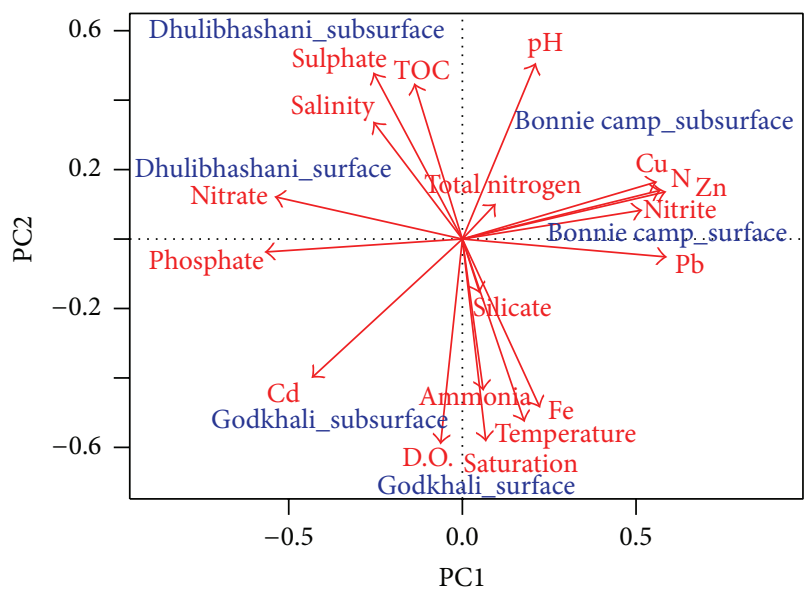

(a)

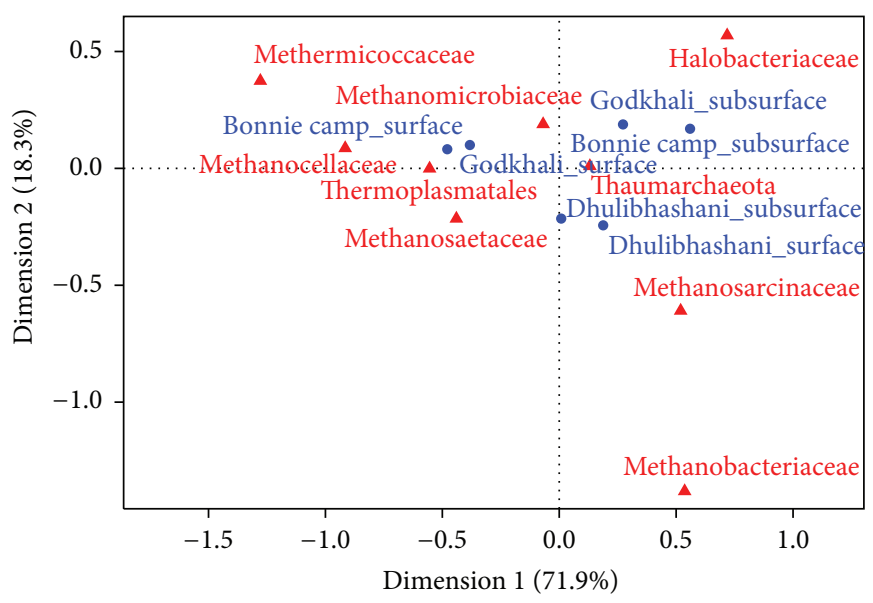

(b)

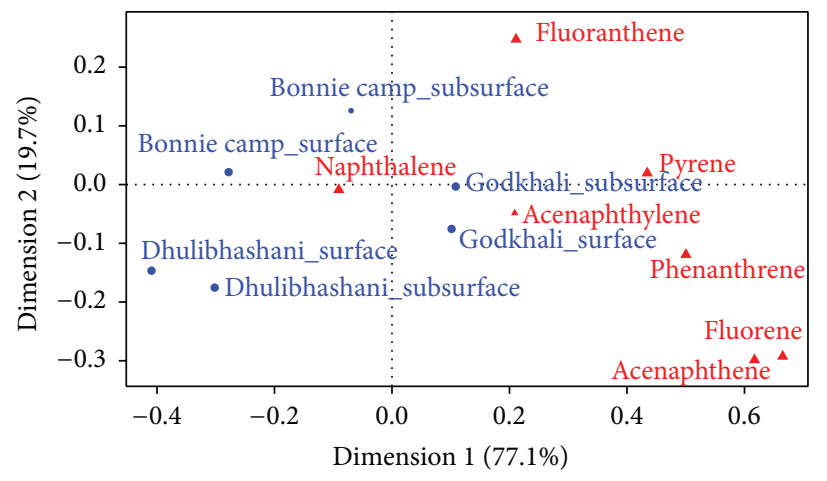

(c)

Figure 4: (a) Principal Component Analysis (PCA) of samples based on environmental parameters, nutrient, and heavy metal levels in the sediments samples. (b) Correspondence analysis (CA) based on distribution of major taxonomic lineages generated analyzing genomic data in the sediment samples. (c) Correspondence analysis (CA) based on distribution of polyaromatic hydrocarbons (PAH) in the sediment samples.

and Bonnie camp, while class Methanomicrobia was found relatively more abundant in Dhulibhashani (Tables 4(b) and $4(\mathrm{c})$ ). Representatives of the class Methanomicrobia, such as Methanolobus, Methanococcoides, Methermicoccus, and Methanocella, were either higher or only present in Dhulibhashani. In contrary, representatives of class Halobacteria such as Halogranum, Halorientalis, Haloferax, and Halarchaeum were either higher or only present in Godkhali/Bonnie camp (Table 4(a)). Putative ammonia-oxidizing archaea in the phylum Thaumarchaeota were highly abundant in all three sampling sites. To our surprise, the order Thermoplasmatales representing acidophilic Euryarchaeota were highly abundant in all three sampling stations despite the fact that the recorded $\mathrm{pH}$ fell between 7.85 and 7.98 in these sites.

\section{Discussion}

In marine environments, microorganisms play an important role in sustainable maintenance of the ecosystem. They are key mediators of global biogeochemical cycling of the essential elements in the marine environments. Recent advancement of molecular microbial ecology has emerged as multiple studies on the diversity and abundance of microorganisms in these habitats and their role in shaping the sustainable ecosystem. Most of these studies focused on marine bacteria and archaea, whereas little is known on the diversity and ecology of mangrove archaea [16, 17, 23, 24]. Interestingly, archaea have been found to be ubiquitous and abundant members of the microbiome in diverse marine environments including coastal waters $[46,47]$, marine sediments, estuaries [48-50], stratified basins [7, 51], mangrove sediments [52$54]$, and open ocean water columns [47, 55]. In marine habitat archaea play crucial roles in nitrification $[54,56,57]$, sulfur metabolism [58], methane oxidation (ANME) [59], and methanogenesis [60].

The present study focused on accessing the archaeal community structure and diversity in the world's largest tropical mangrove sediments of Sundarbans using 16S rRNA gene-based 454-amplicon sequencing. To our knowledge, this is the first study on understanding archaeal diversity in Sundarbans ecosystem. The majority of sequences obtained were affiliated to the Euryarchaeota. Previous studies by Sapp et al. on marine sediment and Wemheuer et al. on German Bight found high abundance of members of Euryarchaeota 


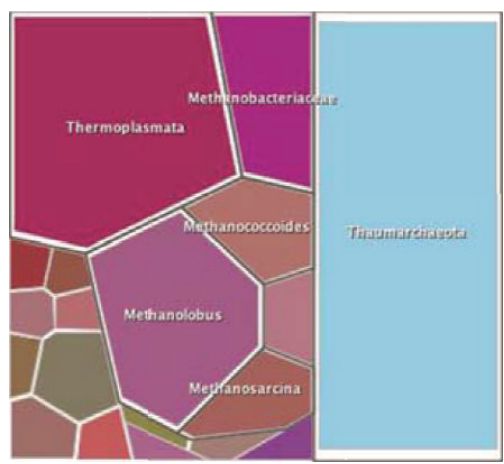

Dhulibhashani_surface

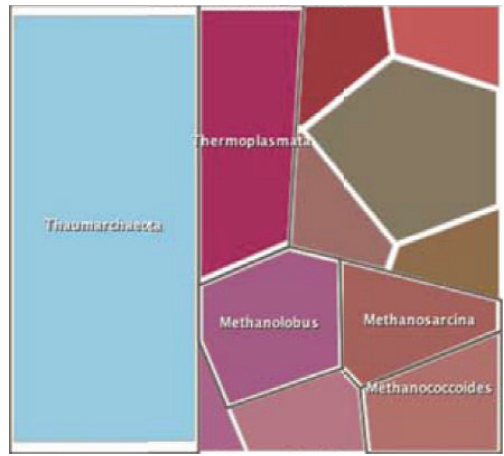

Bonnie camp_subsurface

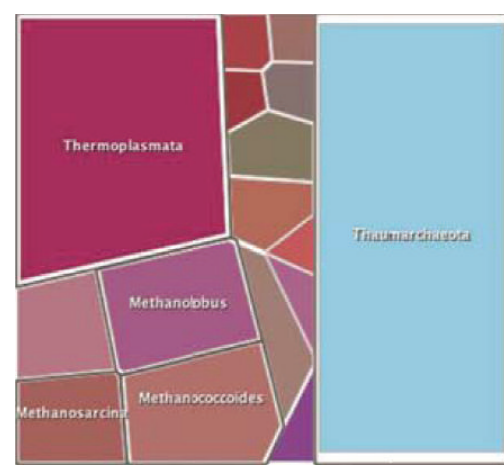

Dhulibhashani_subsurface

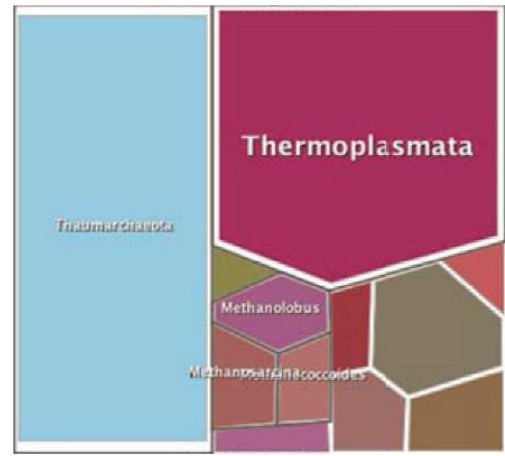

Godkhali_surface

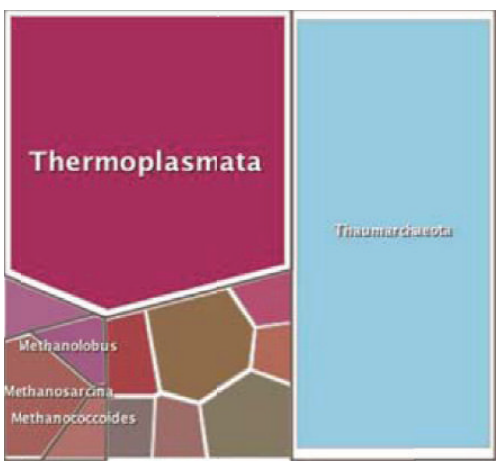

Bonnie camp_surface

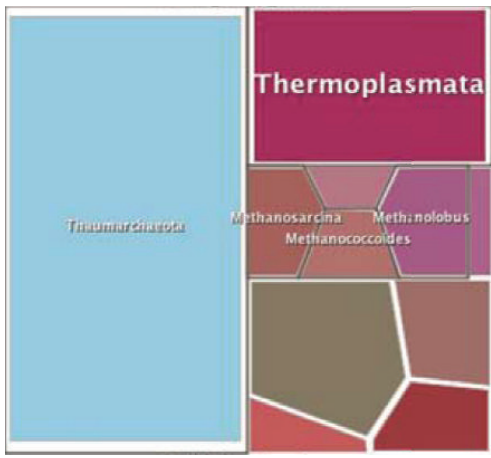

Godkhali_subsurface

FIGURE 5: Voronoi diagram depicting comparative taxonomic profile composition pattern for each sample as a partition of a plane highlighting 6 major phyla.

[35]. We identified Thermoplasmatales as the most abundant euryarchaeal group in the investigated samples. Most sequences were affiliated to the MKCST-A3, CCA47, and VC2.1Arc6 groups. The MKCST-A3 group was first identified in the mangrove sediment of China and most of the members reported so far are uncultured archaeon [16]. The CCA47 group was originally identified by $16 \mathrm{~S}$ rRNA gene analysis of oxygen-depleted marine environment and anoxic subsaline sediments. The number of sequences within this group was also affiliated to the Marine Group II (Euryarchaeota). Previous studies by DeLong and Karl have suggested that the members of Marine Group II are more abundant in temperate sea water than Marine Group I (Thaumarchaeota) [61]. In our case, however, overall abundance of Marine Group I (Thaumarchaeota) is higher compared to Marine Group II (Euryarchaeota) possibly emphasizing geographical differences between tropical and temperate marine sediment microbial community. Moreover, this might also be due to the tidal current that influences the microbial community structure within Sundarbans sediment. The regular inundation of the subtidal zones within Sundarbans whirls up microbial cells to the water column. An in-depth analysis of the archaeal diversity and abundance in the water column might be useful to know whether we could detect a large number of sequences affiliated to Marine Group II. Unfortunately, only limited studies have been performed targeting archaeal communities in the water column in tropical mangrove. Due to such knowledge gap, the habitat preference of
Marine Group II cannot be addressed properly at this time. The Thermoplasmatales cluster VC2.1Arc6 was originally described within the microbial community obtained from in situ growth chamber placed on a deep-sea hydrothermal vent on the Mid-Atlantic Ridge [62]. Besides Thermoplasmatales, the number of euryarchaeal sequences was affiliated to Halobacteria. Members of this group can grow aerobically as well as anaerobically. The majority of the halobacterial sequences analyzed in the present study were affiliated to the Halogranum genus. Besides, a significant number of sequences affiliated to Natronomonas, Haloferax, Halorhabdus, and Halolamina were identified. Methanomicrobia and Methanobacteria were the other two abundant euryarchaeal classes in the investigated samples. Methanomicrobia and Methanobacteria are known for their putative importance in sulfate reduction and methanogenesis in anoxic marine sediments, such as mangroves. The members of these classes are methanogens and are involved in carbon-cycle through methanogenesis.

Beside euryarchaeota, another archaeal group found in all samples was the Marine Group I (MG1) or Thaumarchaeota. Marine Group I (MGI) Thaumarchaeota are one of the most abundant and cosmopolitan chemoautotrophs and prokaryotic picoplankton within the global deep sea water. They were originally identified by sequencing of environmental $16 \mathrm{~S}$ rRNA genes derived from sea water. All organisms of this lineage thus far identified are chemolithoautotrophic ammoniaoxidizers and may play important roles in biogeochemical 
TABLE 4: Results of SIMPER (Similarity Percentage) analyses indicating the contribution of specific taxa to observed differences in archaeal community structure among the stations. (a) shows differences between Godkhali and Bonnie camp; (b) shows differences between Dhulibhashani and Godkhali; and (c) shows differences between Dhulibhashani and Bonnie camp.

(a) Godkhali versus Bonnie camp

\begin{tabular}{|c|c|c|c|c|c|}
\hline Taxon $^{1}$ & Order/family/genus & Contribution $^{2}(\%)$ & $\begin{array}{c}\text { Average }^{3} \% \\
\text { abundance in } \\
\text { Godkhali }\end{array}$ & $\begin{array}{l}\text { Average } \% \text { abundance } \\
\text { in Bonnie camp }\end{array}$ & $\begin{array}{c}\text { Average } \\
\text { dissimilarities }\end{array}$ \\
\hline Thermoplasmata & Thermoplasmatales & 23.30 & 4.85 & 4.64 & 5.23 \\
\hline Halobacteria & Halogranum & 11.72 & 1.50 & 1.64 & 2.63 \\
\hline Thaumarchaeota & Thaumarchaeota & 10.08 & 8.29 & 7.99 & 2.26 \\
\hline Methanomicrobia & Methanolobus & 8.33 & 0.65 & 0.99 & 1.87 \\
\hline Methanomicrobia & Methanococcoides & 6.46 & 0.40 & 0.82 & 1.45 \\
\hline Halobacteria & Haloferax & 5.42 & 0.48 & 0.47 & 1.22 \\
\hline Halobacteria & Natronomonas & 5.41 & 0.62 & 0.73 & 1.21 \\
\hline Methanomicrobia & Methanosarcina & 5.00 & 0.55 & 1.03 & 1.12 \\
\hline Halobacteria & Halorhabdus & 3.97 & 0.35 & 0.35 & 0.89 \\
\hline Halobacteria & Halolamina & 3.49 & 0.38 & 0.30 & 0.78 \\
\hline Methanomicrobia & Methanosalsum & 3.46 & 0.13 & 0.33 & 0.78 \\
\hline Halobacteria & Halarchaeum & 3.17 & 0.08 & 0.30 & 0.71 \\
\hline Halobacteria & Halorientalis & 2.17 & 0.19 & 0.16 & 0.49 \\
\hline
\end{tabular}

(b) Dhulibhashani versus Godkhali

\begin{tabular}{|c|c|c|c|c|c|}
\hline Taxon $^{1}$ & Order/family/genus & Contribution $^{2}(\%)$ & $\begin{array}{c}\text { Average }^{3} \% \\
\text { abundance in } \\
\text { Dhulibhashani }\end{array}$ & $\begin{array}{l}\text { Average } \% \text { abundance } \\
\text { in Godkhali }\end{array}$ & $\begin{array}{c}\text { Average } \\
\text { dissimilarities }\end{array}$ \\
\hline Methanomicrobia & Methanolobus & 19.80 & 2.34 & 0.65 & 4.28 \\
\hline Thermoplasmata & Thermoplasmatales & 18.75 & 4.59 & 4.85 & 4.05 \\
\hline Methanomicrobia & Methanococcoides & 12.14 & 1.43 & 0.40 & 2.62 \\
\hline Thaumarchaeota & Thaumarchaeota & 9.64 & 8.29 & 8.29 & 2.08 \\
\hline Halobacteria & Halogranum & 8.80 & 0.75 & 1.50 & 1.90 \\
\hline Methanomicrobia & Methermicoccus & 4.02 & 0.34 & 0.00 & 0.87 \\
\hline Methanomicrobia & Methanosalsum & 3.84 & 0.45 & 0.13 & 0.83 \\
\hline Halobacteria & Haloferax & 3.58 & 0.18 & 0.48 & 0.77 \\
\hline Halobacteria & Natronomonas & 3.49 & 0.42 & 0.62 & 0.75 \\
\hline Methanomicrobia & Methanocella & 2.47 & 0.21 & 0.00 & 0.53 \\
\hline Halobacteria & Halorientalis & 2.20 & 0.00 & 0.19 & 0.47 \\
\hline Halobacteria & Halolamina & 1.90 & 0.24 & 0.38 & 0.41 \\
\hline
\end{tabular}

(c) Dhulibhashani versus Bonnie camp

\begin{tabular}{|c|c|c|c|c|c|}
\hline Taxon $^{1}$ & Order/family/genus & Contribution $^{2}(\%)$ & $\begin{array}{c}\text { Average }^{3} \% \\
\text { abundance in station } \\
\text { A }\end{array}$ & $\begin{array}{c}\text { Average } \% \text { abundance } \\
\text { in station B }\end{array}$ & $\begin{array}{c}\text { Average } \\
\text { dissimilarities }\end{array}$ \\
\hline Thermoplasmata & Thermoplasmatales & 20.76 & 4.59 & 4.64 & 5.12 \\
\hline Methanomicrobia & Methanolobus & 14.23 & 2.34 & 0.99 & 3.51 \\
\hline Halobacteria & Halogranum & 10.05 & 0.75 & 1.64 & 2.48 \\
\hline Methanomicrobia & Methanococcoides & 8.65 & 1.43 & 0.82 & 2.13 \\
\hline Thaumarchaeota & Thaumarchaeota & 6.72 & 8.29 & 7.99 & 1.66 \\
\hline Halobacteria & Natronomonas & 4.73 & 0.42 & 0.73 & 1.17 \\
\hline Halobacteria & Haloferax & 4.42 & 0.18 & 0.47 & 1.09 \\
\hline Methanomicrobia & Methanosarcina & 3.96 & 0.70 & 1.03 & 0.98 \\
\hline Methanomicrobia & Methermicoccus & 3.42 & 0.34 & 0.00 & 0.84 \\
\hline Methanomicrobia & Methanosalsum & 3.40 & 0.45 & 0.33 & 0.84 \\
\hline Halobacteria & Halorhabdus & 3.37 & 0.24 & 0.35 & 0.83 \\
\hline Halobacteria & Halolamina & 2.92 & 0.24 & 0.30 & 0.72 \\
\hline
\end{tabular}


(c) Continued.

\begin{tabular}{|c|c|c|c|c|c|}
\hline Taxon $^{1}$ & Order/family/genus & Contribution $^{2}(\%)$ & $\begin{array}{c}\text { Average }^{3} \% \\
\text { abundance in station } \\
\text { A }\end{array}$ & $\begin{array}{l}\text { Average } \% \text { abundance } \\
\text { in station B }\end{array}$ & $\begin{array}{c}\text { Average } \\
\text { dissimilarities }\end{array}$ \\
\hline Halobacteria & Halarchaeum & 2.70 & 0.00 & 0.30 & 0.67 \\
\hline Methanomicrobia & Methanocella & 2.10 & 0.21 & 0.00 & 0.52 \\
\hline
\end{tabular}

${ }^{1}$ Phylum or class level for archaea.

${ }^{2}$ Contribution of each taxon to the overall dissimilarity between these two clusters.

${ }^{3}$ Average abundance of each taxon in the two clusters.

cycles, such as the nitrogen cycle and the carbon cycle. Within our sequence dataset, the number of ammonia oxidizing Thaumarchaeota was identified.

We observed an increased abundance of Halobacteriaceae in the investigated subsurface samples from Godkhali and Bonnie camp. In contrary, the number of Methanosarcinaceae and Methanobacteriaceae was higher in the samples derived from Dhulibhashani. This might be correlated with the high amounts of organic matter in resident algal blooms in Godkhali and Bonnie camp (Figures 4(b) and 4(c)). Furthermore, correspondence analysis revealed that detected PAHs were mostly correlated to the surface and subsurface sediments of Godkhali and Bonnie camp. Previous studies from our group have shown that in Godkhali and Bonnie camp, because of the presence of jetty for transportation, large amount of hydrocarbon-derived chemicals and oils are released in water and in turn increase algal blooms in surrounding areas (Personal Communication). To this end, we believe that abundance of Halobacteriaceae in Godkhali and Bonnie camp corroborates well to inflated detection PAHs in the sediment. In hypersaline environment, Halobacteria are the most active organisms capable of organic matter degradation. Thus the higher abundance of Halobacteria in Godkhali and Bonnie camp might indicate an involvement in marine organic matter degradation under high nutrient conditions found during algal blooms. Similar results were reported by Teeling et al., where they demonstrated that bacterial community structures were highly influenced by the presence of an algal bloom [63]. Furthermore, Wemheuer et al. have recently demonstrated that archaeal diversity was influenced by algal blooms in German Bight [35]. Taken together, present observation indicates that marine microbial communities are influenced by algal blooms or by environmental parameters correlated with bloom presence.

\section{Conclusions}

In summary, the spatial variations of the sedimentary archaeal diversity have been studied in the Sundarbans mangrove ecosystem for the first time by means of $16 \mathrm{~S}$ rRNA 454-pyrosequencing. We found highly diverse archaeal communities in the sediment of Sundarbans. Our analyses have confirmed the influence of environment in shaping the archaeal community diversity within the sediment. However, due to the lack of pure cultures and large comparative investigations, robust conclusions related to the involvement of identified archaeal communities in biogeochemical cycle cannot be drawn. Further research including analyses of expression of functional genes and determination of the active archaeal population within the sediment might unravel the role of archaea in Sundarbans mangrove ecosystem.

\section{Conflict of Interests}

The authors declare that there is no conflict of interests regarding the publication of this paper.

\section{Acknowledgments}

The authors would like to acknowledge the instrument facility provided by World Bank, ICZM Project, in the Department of Biochemistry, University of Calcutta, India. Anish Bhattacharyya, Debojyoti Roy, and Sudip Nag were supported with Research Fellowships from the ICZM Project, World Bank. Abhrajyoti Ghosh was supported by Ramanujan Fellowship from Department of Science and Technology, India (SR/S2/RJN-106/2012) and an extramural grant (no. 38(1391)/14/EMR-II) from the Council of Scientific \& Industrial Research (CSIR), Government of India.

\section{References}

[1] S.-V. Albers, P. Forterre, D. Prangishvili, and C. Schleper, "The legacy of Carl Woese and Wolfram Zillig: from phylogeny to landmark discoveries," Nature Reviews Microbiology, vol. 11, no. 10, pp. 713-719, 2013.

[2] K. F. Jarrell, A. D. Walters, C. Bochiwal, J. M. Borgia, T. Dickinson, and J. P. J. Chong, "Major players on the microbial stage: why Archaea are important," Microbiology, vol. 157, no. 4, pp. 919-936, 2011.

[3] E. F. DeLong, "Archaea in coastal marine environments," Proceedings of the National Academy of Sciences of the United States of America, vol. 89, no. 12, pp. 5685-5689, 1992.

[4] K. Takai and K. Horikoshi, "Genetic diversity of archaea in deep-sea hydrothermal vent environments," Genetics, vol. 152, no. 4, pp. 1285-1297, 1999.

[5] J. L. Macalady, D. S. Jones, and E. H. Lyon, "Extremely acidic, pendulous cave wall biofilms from the Frasassi cave system, Italy," Environmental Microbiology, vol. 9, no. 6, pp. 1402-1414, 2007.

[6] A. Gittel, K. B. Sørensen, T. L. Skovhus, K. Ingvorsen, and A. Schramm, "Prokaryotic community structure and sulfate reducer activity in water from high-temperature oil reservoirs with and without nitrate treatment," Applied and Environmental Microbiology, vol. 75, no. 22, pp. 7086-7096, 2009. 
[7] M. J. L. Coolen, B. Abbas, J. van Bleijswijk et al., "Putative ammonia-oxidizing Crenarchaeota in suboxic waters of the Black Sea: a basin-wide ecological study using $16 \mathrm{~S}$ ribosomal and functional genes and membrane lipids," Environmental Microbiology, vol. 9, no. 4, pp. 1001-1016, 2007.

[8] J. Borneman and E. W. Triplett, "Molecular microbial diversity in soils from eastern Amazonia: evidence for unusual microorganisms and microbial population shifts associated with deforestation," Applied and Environmental Microbiology, vol. 63, no. 7, pp. 2647-2653, 1997.

[9] D. H. Buckley, J. R. Graber, and T. M. Schmidt, "Phylogenetic analysis of nonthermophilic members of the kingdom Crenarchaeota and their diversity and abundance in soils," Applied and Environmental Microbiology, vol. 64, no. 11, pp. 4333-4339, 1998.

[10] G. Jurgens, K. Lindström, and A. Saano, "Novel group within the kingdom Crenarchaeota from boreal forest soil," Applied and Environmental Microbiology, vol. 63, no. 2, pp. 803-805, 1997.

[11] R. Massana, A. E. Murray, C. M. Preston, and E. F. DeLong, "Vertical distribution and phylogenetic characterization of marine planktonic Archaea in the Santa Barbara Channel," Applied and Environmental Microbiology, vol. 63, no. 1, pp. 5056, 1997.

[12] C. Schleper, W. Holben, and H.-P. Klenk, "Recovery of crenarchaeotal ribosomal DNA sequences from freshwater-lake sediments," Applied and Environmental Microbiology, vol. 63, no. 1, pp. 321-323, 1997.

[13] E. F. DeLong and N. R. Pace, "Environmental diversity of bacteria and archaea," Systematic Biology, vol. 50, no. 4, pp. 470478, 2001.

[14] K. Knittel, T. Lösekann, A. Boetius, R. Kort, and R. Amann, "Diversity and distribution of methanotrophic archaea at cold seeps," Applied and Environmental Microbiology, vol. 71, no. 1, pp. 467-479, 2005.

[15] R. Margesin and V. Miteva, "Diversity and ecology of psychrophilic microorganisms," Research in Microbiology, vol. 162, no. 3, pp. 346-361, 2011.

[16] B. Yan, K. Hong, and Z.-N. Yu, "Archaeal communities in mangrove soil characterized by $16 \mathrm{~S}$ rRNA gene clones," Journal of Microbiology, vol. 44, no. 5, pp. 566-571, 2006.

[17] T. J. Lyimo, A. Pol, M. S. M. Jetten, and H. J. M. Op den Camp, "Diversity of methanogenic archaea in a mangrove sediment and isolation of a new Methanococcoides strain: research Letter," FEMS Microbiology Letters, vol. 291, no. 2, pp. 247-253, 2009.

[18] G. Holguin, P. Vazquez, and Y. Bashan, "The role of sediment microorganisms in the productivity, conservation, and rehabilitation of mangrove ecosystems: an overview," Biology and Fertility of Soils, vol. 33, no. 4, pp. 265-278, 2001.

[19] S. Das, M. De, T. K. Jana, and T. K. De, "Environmental influence on cultivable microbial community in the sediment of Sundarban mangrove forest, India," African Journal of Microbiology Research, vol. 7, no. 38, pp. 4655-4665, 2013.

[20] S. Das, P. S. Lyla, and S. A. Khan, "Marine microbial diversity and ecology: importance and future perspectives," Current Science, vol. 90, no. 10, pp. 1325-1335, 2006.

[21] A. Ghosh, N. Dey, A. Bera et al., "Culture independent molecular analysis of bacterial communities in the mangrove sediment of Sundarban, India," Saline Systems, vol. 6, no. 1, article 1, 2010.

[22] A. Chakraborty, A. Bera, A. Mukherjee et al., "Changing bacterial profile of Sundarbans, the world heritage mangrove: impact of anthropogenic interventions," World Journal of Microbiology and Biotechnology, vol. 31, no. 4, pp. 593-610, 2015.
[23] P. Basak, N. S. Majumder, S. Nag et al., "Spatiotemporal analysis of bacterial diversity in sediments of Sundarbans using parallel 16S rRNA gene tag sequencing," Microbial Ecology, vol. 69, no. 3, pp. 500-511, 2014.

[24] X.-T. Jiang, X. Peng, G.-H. Deng et al., "Illumina Sequencing of $16 \mathrm{~S}$ rRNA Tag Revealed Spatial Variations of Bacterial Communities in a Mangrove Wetland," Microbial Ecology, vol. 66, no. 1, pp. 96-104, 2013.

[25] F. L. D. D. Sebastianes, A. S. Romão-Dumaresq, P. T. Lacava et al., "Species diversity of culturable endophytic fungi from Brazilian mangrove forests," Current Genetics, vol. 59, no. 3, pp. 153-166, 2013.

[26] Y. Arfi, M. Buée, C. Marchand, A. Levasseur, and E. Record, "Multiple markers pyrosequencing reveals highly diverse and host-specific fungal communities on the mangrove trees Avicennia marinaand Rhizophora stylosa," FEMS Microbiology Ecology, vol. 79, no. 2, pp. 433-444, 2012.

[27] T. J. Lyimo, A. Pol, M. S. M. Jetten, and H. J. M. Op Den Camp, "Diversity of methanogenic archaea in a mangrove sediment and isolation of a new Methanococcoides strain," FEMS Microbiology Letters, vol. 291, no. 2, pp. 247-253, 2009.

[28] A. C. C. Pires, D. F. R. Cleary, A. Almeida et al., "Denaturing gradient gel electrophoresis and barcoded pyrosequencing reveal unprecedented archaeal diversity in mangrove sediment and rhizosphere samples," Applied and Environmental Microbiology, vol. 78, no. 16, pp. 5520-5528, 2012.

[29] D. W. Nelson and L. E. Somers, Organic Carbon, Academic Press, London, UK, 1975.

[30] C. A. Black, Methods of Soil Analysis, American Society of Agronomy, Madison, Wis, USA, 1965.

[31] M. Knudsen, Hydrographical Tables, GEC GAD, Copenhagen, Denmark, 1901.

[32] A. Knap, A. Michaels, A. Close, H. Ducklow, and A. Dickson, Eds., Protocols for the Joint Global Ocean Flux Study (JGOFS) Core Measurements, JGOFS Report No. 19, 1996.

[33] I. Bragança, A. Plácido, P. Paíga, V. F. Domingues, and C. Delerue-Matos, "QuEChERS: a new sample preparation approach for the determination of ibuprofen and its metabolites in soils," Science of the Total Environment, vol. 433, pp. 281-289, 2012.

[34] L. Correia-Sá, V. C. Fernandes, M. Carvalho, C. Calhau, V. M. F. Domingues, and C. Delerue-Matos, "Optimization of QuEChERS method for the analysis of organochlorine pesticides in soils with diverse organic matter," Journal of Separation Science, vol. 35, no. 12, pp. 1521-1530, 2012.

[35] B. Wemheuer, F. Wemheuer, and R. Daniel, "RNA-based assessment of diversity and composition of active archaeal communities in the German Bight," Archaea, vol. 2012, Article ID 695826, 8 pages, 2012.

[36] E. Pruesse, C. Quast, K. Knittel et al., "SILVA: a comprehensive online resource for quality checked and aligned ribosomal RNA sequence data compatible with ARB," Nucleic Acids Research, vol. 35, no. 21, pp. 7188-7196, 2007.

[37] S. F. Altschul, W. Gish, W. Miller, E. W. Myers, and D. J. Lipman, "Basic local alignment search tool," Journal of Molecular Biology, vol. 215, no. 3, pp. 403-410, 1990.

[38] D. H. Huson, S. Mitra, H.-J. Ruscheweyh, N. Weber, and S. C. Schuster, "Integrative analysis of environmental sequences using MEGAN4," Genome Research, vol. 21, no. 9, pp. 1552-1560, 2011. 
[39] S. Mitra, M. Stärk, and D. H. Huson, "Analysis of 16 S rRNA environmental sequences using MEGAN," BMC Genomics, vol. 12, supplement 3, p. S17, 2011.

[40] R Core Team, R: A Language and Environment for Statistical Computing, R Foundation for Statistical Computing, Vienna, Austria, 2014.

[41] S. K. Sarkar, B. Bhattacharya, S. Debnath, G. Bandopadhaya, and S. Giri, "Heavy metals in biota from Sundarban Wetland Ecosystem, India: implications to monitoring and environmental assessment," Aquatic Ecosystem Health \& Management, vol. 5, no. 4, pp. 467-472, 2002.

[42] M. T. Rahman, M. S. Rahman, S. B. Quraishi, J. U. Ahmad, T. R. Choudhury, and M. A. Mottaleb, "Distribution of heavy metals in water and sediments in Passur River, Sundarban Mangrove Forest, Bangladesh," Journal of International Environmental Application \& Science, vol. 6, no. 4, pp. 537-546, 2011.

[43] M. Saha, S. K. Sarkar, and B. Bhattacharya, "Interspecific variation in heavy metal body concentrations in biota of Sunderban mangrove wetland, northeast India," Environment International, vol. 32, no. 2, pp. 203-207, 2006.

[44] K. Banerjee, B. Senthilkumar, R. Purvaja, and R. Ramesh, "Sedimentation and trace metal distribution in selected locations of Sundarbans mangroves and Hooghly estuary, Northeast coast of India," Environmental Geochemistry and Health, vol. 34, no. 1, pp. 27-42, 2012.

[45] S. Massolo, A. Bignasca, S. K. Sarkar, M. Chatterjee, B. D. Bhattacharya, and A. Alam, "Geochemical fractionation of trace elements in sediments of Hugli River (Ganges) and Sundarban wetland (West Bengal, India)," Environmental Monitoring and Assessment, vol. 184, no. 12, pp. 7561-7577, 2012.

[46] T. J. Mincer, M. J. Church, L. T. Taylor, C. Preston, D. M. Karl, and E. F. DeLong, "Quantitative distribution of presumptive archaeal and bacterial nitrifiers in Monterey Bay and the North Pacific Subtropical Gyre," Environmental Microbiology, vol. 9, no. 5, pp. 1162-1175, 2007.

[47] J. M. Beman, B. N. Popp, and C. A. Francis, "Molecular and biogeochemical evidence for ammonia oxidation by marine Crenarchaeota in the Gulf of California," The ISME Journal, vol. 2, no. 4, pp. 429-441, 2008.

[48] A. C. Mosier and C. A. Francis, "Relative abundance and diversity of ammonia-oxidizing archaea and bacteria in the San Francisco Bay estuary," Environmental Microbiology, vol. 10, no. 11, pp. 3002-3016, 2008.

[49] A. E. Bernhard, Z. C. Landry, A. Blevins, J. R. de la Torre, A. E. Giblin, and D. A. Stahl, "Abundance of ammonia-oxidizing archaea and bacteria along an estuarine salinity gradient in relation to potential nitrification rates," Applied and Environmental Microbiology, vol. 76, no. 4, pp. 1285-1289, 2010.

[50] H. Urakawa, W. Martens-Habbena, and D. A. Stahl, "High abundance of ammonia-oxidizing archaea in coastal waters, determined using a modified DNA extraction method," Applied and Environmental Microbiology, vol. 76, no. 7, pp. 2129-2135, 2010.

[51] P. Lam, M. M. Jensen, G. Lavik et al., "Linking crenarchaeal and bacterial nitrification to anammox in the Black Sea," Proceedings of the National Academy of Sciences of the United States of America, vol. 104, no. 17, pp. 7104-7109, 2007.

[52] Y.-F. Wang, Y.-Y. Feng, X. Ma, and J.-D. Gu, "Seasonal dynamics of ammonia/ammonium-oxidizing prokaryotes in oxic and anoxic wetland sediments of subtropical coastal mangrove," Applied Microbiology and Biotechnology, vol. 97, no. 17, pp. 79197934, 2013.
[53] M. Li, Y.-G. Hong, H.-L. Cao, and J.-D. Gu, "Mangrove trees affect the community structure and distribution of anammox bacteria at an anthropogenic-polluted mangrove in the Pearl River Delta reflected by $16 \mathrm{~S}$ rRNA and hydrazine oxidoreductase (HZO) encoding gene analyses," Ecotoxicology, vol. 20, no. 8, pp. 1780-1790, 2011.

[54] H. Cao, M. Li, Y. Hong, and J.-D. Gu, "Diversity and abundance of ammonia-oxidizing archaea and bacteria in polluted mangrove sediment," Systematic and Applied Microbiology, vol. 34, no. 7, pp. 513-523, 2011.

[55] M. J. Church, B. Wai, D. M. Karl, and E. F. DeLong, "Abundances of crenarchaeal amoA genes and transcripts in the Pacific Ocean," Environmental Microbiology, vol. 12, no. 3, pp. 679-688, 2010.

[56] D. A. Stahl and J. R. de la Torre, "Physiology and diversity of ammonia-oxidizing archaea," Annual Review of Microbiology, vol. 66, pp. 83-101, 2012.

[57] H. Cao, J.-C. Auguet, and J.-D. Gu, "Global ecological pattern of ammonia-oxidizing archaea," PLoS ONE, vol. 8, no. 2, Article ID e52853, 2013.

[58] Y. Zhang, Z. Zhao, C.-T. A. Chen, K. Tang, J. Su, and N. Jiao, "Sulfur metabolizing microbes dominate microbial communities in Andesite-hosted shallow-sea hydrothermal systems," PLoS ONE, vol. 7, no. 9, Article ID e44593, 2012.

[59] J. Milucka, T. G. Ferdelman, L. Polerecky et al., "Zero-valent sulphur is a key intermediate in marine methane oxidation," Nature, vol. 491, no. 7425, pp. 541-546, 2012.

[60] K. Knittel and A. Boetius, "Anaerobic oxidation of methane: progress with an unknown process," Annual Review of Microbiology, vol. 63, pp. 311-334, 2009.

[61] E. F. DeLong and D. M. Karl, "Genomic perspectives in microbial oceanography," Nature, vol. 437, no. 7057, pp. 336-342, 2005.

[62] A.-L. Reysenbach, K. Longnecker, and J. Kirshtein, "Novel bacterial and archaeal lineages from an in situ growth chamber deployed at a mid-atlantic ridge hydrothermal vent," Applied and Environmental Microbiology, vol. 66, no. 9, pp. 3798-3806, 2000.

[63] H. Teeling, B. M. Fuchs, D. Becher et al., "Substrate-controlled succession of marine bacterioplankton populations induced by a phytoplankton bloom," Science, vol. 336, no. 6081, pp. 608-611, 2012. 

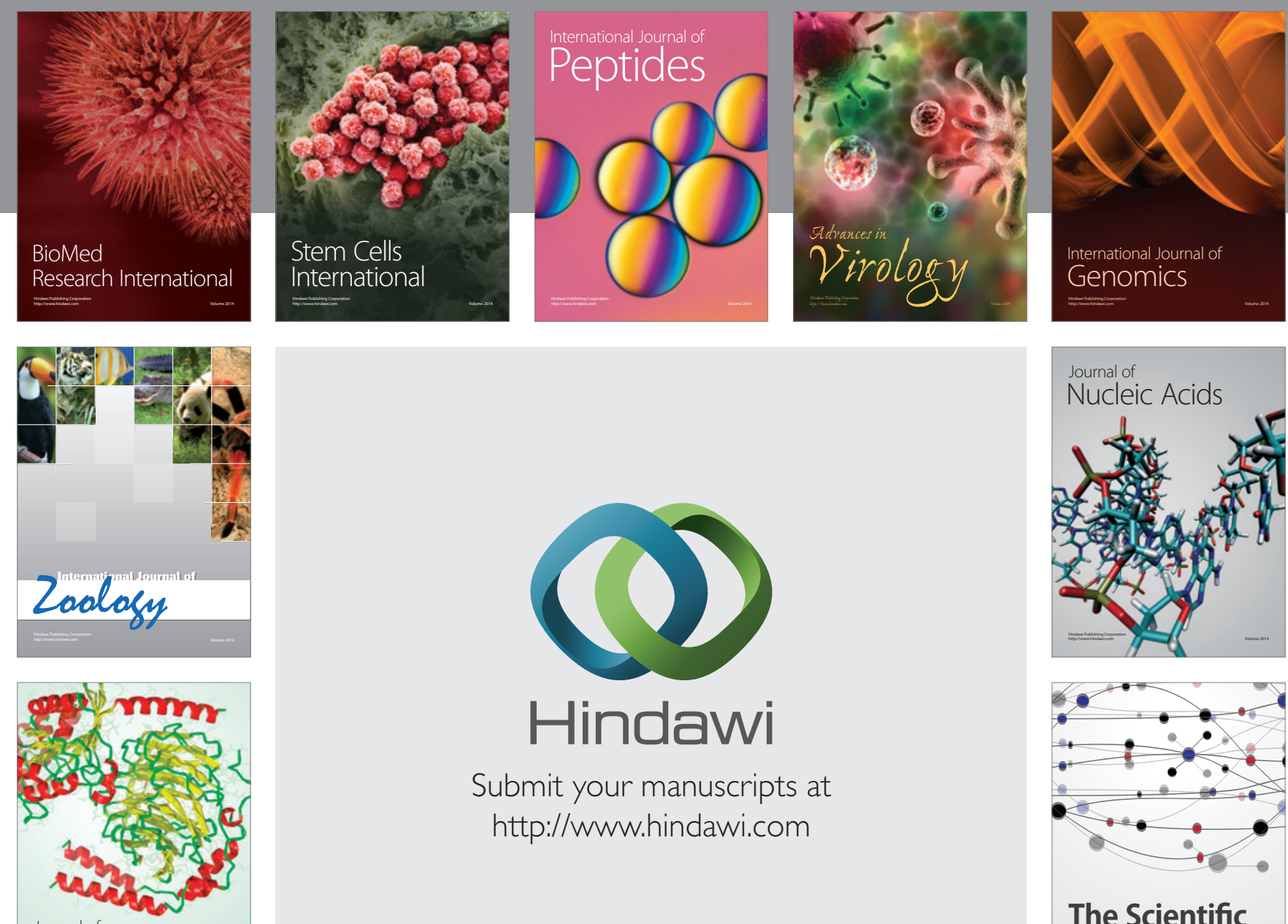

Submit your manuscripts at

http://www.hindawi.com

Journal of
Signal Transduction
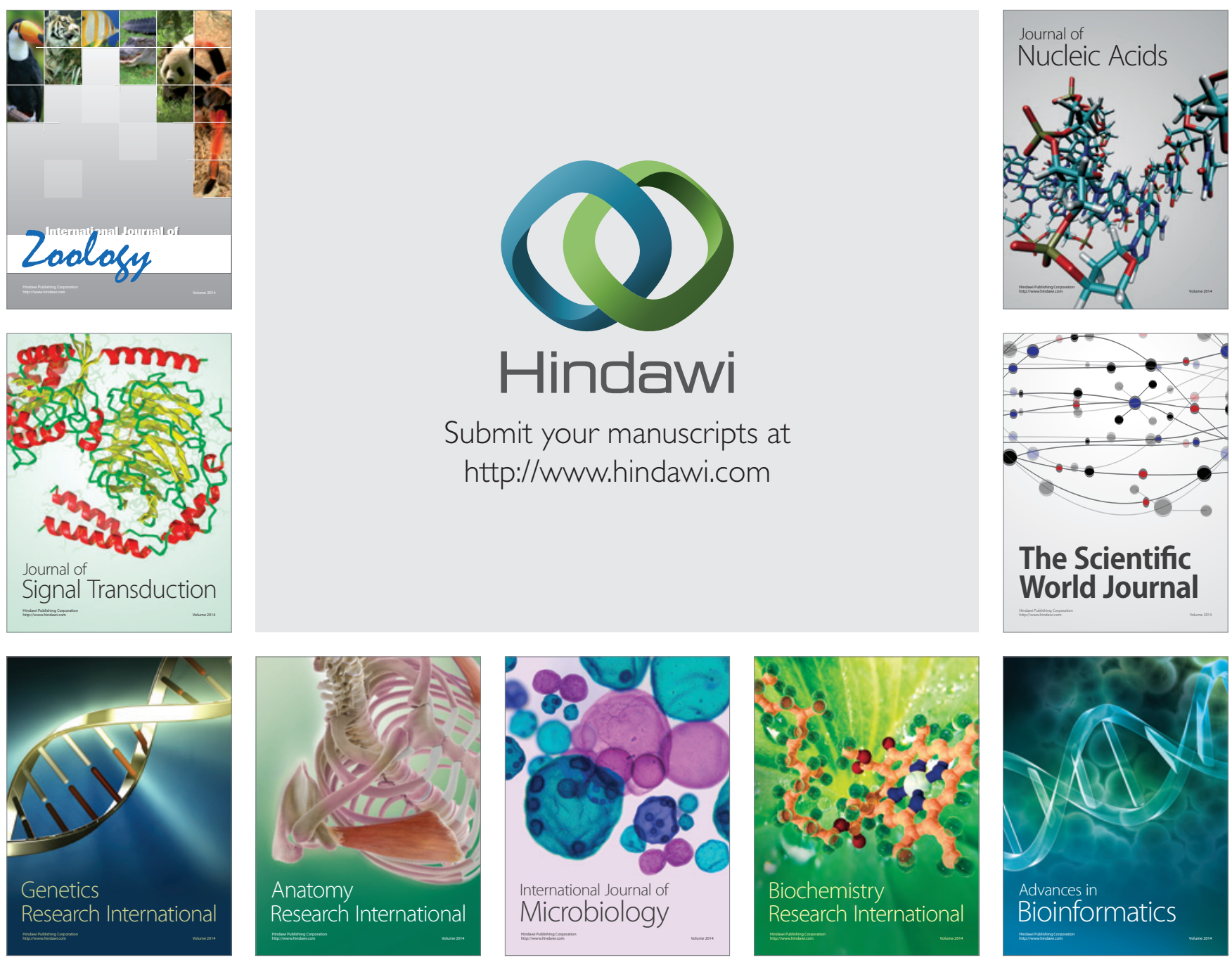

The Scientific World Journal
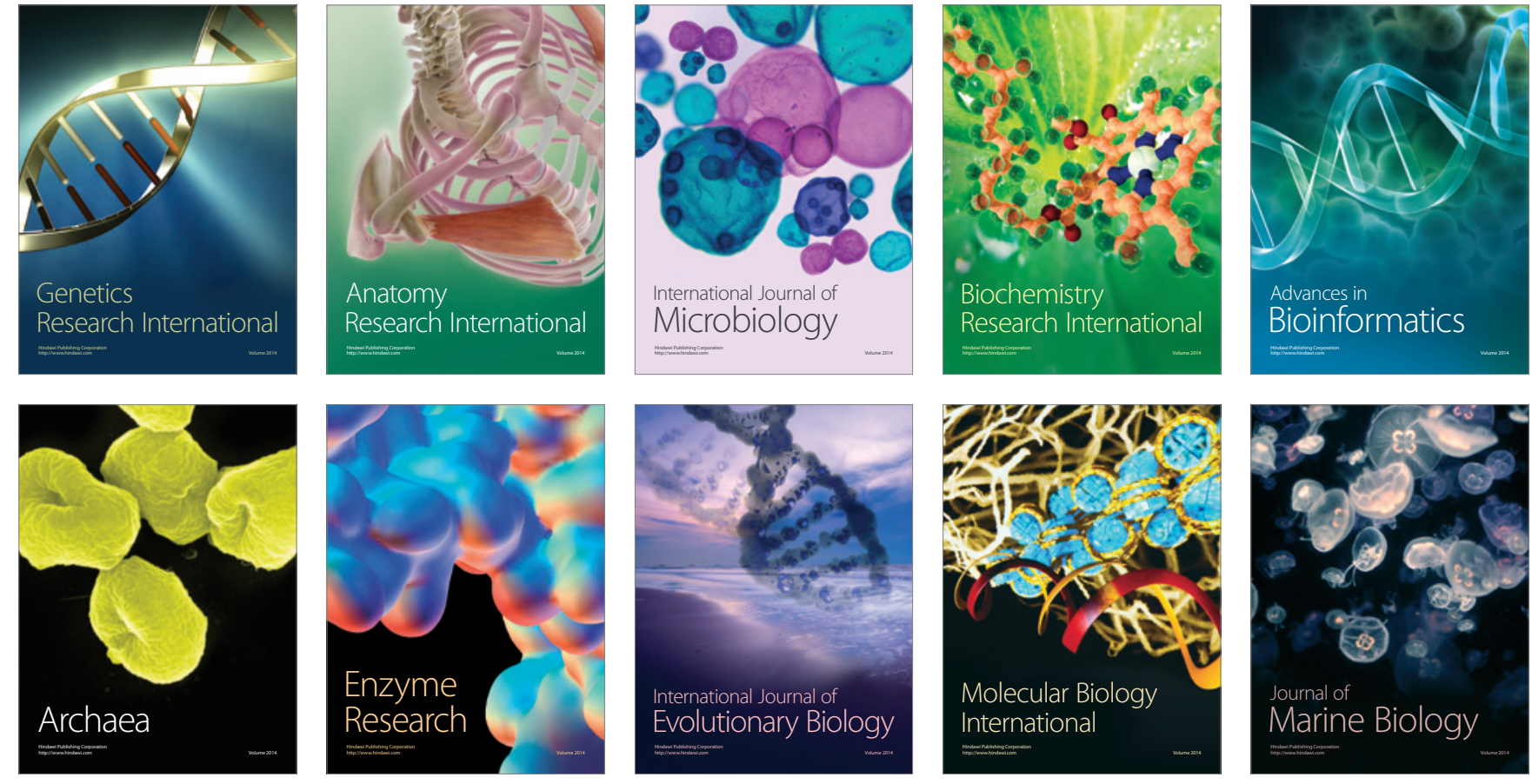